PNL --8544

DE93 009821

\title{
Project Status Report
}

\section{Polish-American Children's Hospital in Krakow, Poland}

\author{
T. J. Secrest \\ R. F. Szydlowski \\ D. Wade ${ }^{(a)}$
}

\section{March 1993}

Prepared for the

U.S. Department of Energy

under Contract DE-AC06-76RLO 1830

Pacific Northwest Laboratory

Richland, Washington 99352

\footnotetext{
(a) RDA Engineering, Inc.,
Marietta, Georgia 30060

(a) RDA Engineering, Inc.,
Marietta, Georgia 30060
}

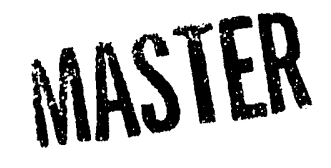




\section{Summary}

The Department of Energy's Office of Technical and Financial Assistance funded an examination of the Polish-American Children's Hospital located in Krakow, Poland, to identify energy efficiency actions that could be implemented. A walk-through audit was conducted to assess actions applicable to the Hospital's energy supply and consuming systems. The costs of identified actions were not developed as part of this assessment.

The Hospital operates a coal-fired boiler plant and a natural-gas-fired steam plant that provide thermal energy for space heating and sterilization. Additional thermal energy for supplemental space heating is purchased from the local district heating company. Electricity is used primarily for lighting and for operating hospital equipment.

Before making any improvements to the Hospital's physical systems, a complete characterization of the thermal systems is deemed necessary to plan the recommended physical improvements. The characterization will also enable the hospital to more efficiently meet increased thermal energy requirements from facility additions that are planned and under way.

Improvements identified were classified by lower cost and high cost; no no-cost improvements were identified. The lower cost improvements are:

- implement a water treatment program to reduce heat exchanger fouling

- upgrade the control systems

- reduce the high temperature hot water supply temperature from the main power plant and use booster heaters and modify operations accordingly

- develop and implement an operation and maintenance program to address problem and opportunity areas.

The higher cost improvement is to upgrade the main power plant. Another action may be to negotiate with the district heating company to operate the main power plant. No actions applicable to reducing electricity use were identified. 


\section{Acknowledgments}

Mr. Jan Zasowski, the Hospital Director of Engineering, was very cooperative and helpful in providing the time to host our visit and answer our many questions.

This report is one of several energy efficiency assessments in Eastern Europe managed by the Advanced Internation Studies Unit of the Pacific Northwest Laboratory, operated for the U.S.

Department of Energy (DOE) by Battelle Memorial Institute. Support for this effort was provided by the Institutional Conservation Program of the Office of Technical and Financial Assistance (OTFA), DOE. Appreciation is expressed to Edna Jones, OTFA, for her support and encouragement. 


\section{Contents}

Summary $\ldots \ldots \ldots \ldots \ldots \ldots \ldots \ldots \ldots \ldots \ldots \ldots \ldots \ldots \ldots \ldots \ldots \ldots \ldots$ iii

Acknowledgments $\ldots \ldots \ldots \ldots \ldots \ldots \ldots \ldots \ldots \ldots \ldots \ldots \ldots \ldots \ldots$

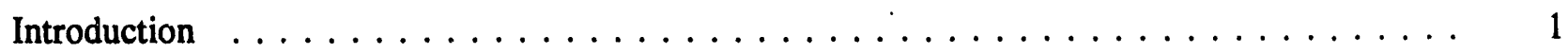

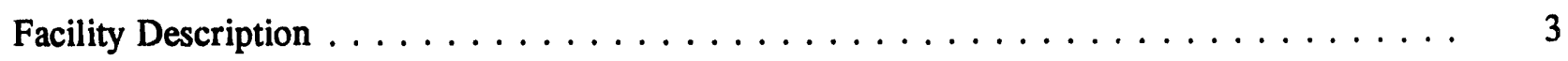

Facility Overview $\ldots \ldots \ldots \ldots \ldots \ldots \ldots \ldots \ldots \ldots \ldots \ldots \ldots \ldots \ldots \ldots \ldots$

Thermal System Overview $\ldots \ldots \ldots \ldots \ldots \ldots \ldots \ldots \ldots \ldots \ldots$

First Hospital Section $\ldots \ldots \ldots \ldots \ldots \ldots \ldots \ldots \ldots \ldots \ldots \ldots \ldots \ldots \ldots \ldots \ldots$

Second Hospital Section $\ldots \ldots \ldots \ldots \ldots \ldots \ldots \ldots \ldots \ldots \ldots \ldots \ldots \ldots \ldots \ldots$

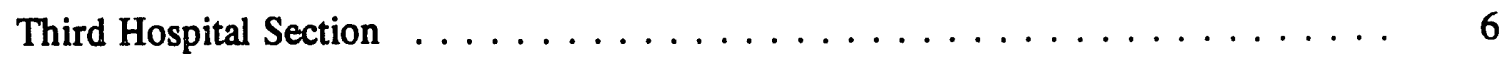

Fourth Hospital Section $\ldots \ldots \ldots \ldots \ldots \ldots \ldots \ldots \ldots \ldots \ldots$

Medical Academy Campus . . . . . . . . . . . . . 7

Main HTHW Power Plant $\ldots \ldots \ldots \ldots \ldots \ldots \ldots \ldots \ldots$

Hospital Laundry Steam Power Plant $\ldots \ldots \ldots \ldots \ldots \ldots \ldots \ldots$

HTHW and Heating Water Quality $\ldots \ldots \ldots \ldots \ldots \ldots \ldots \ldots$

Comments, Issues, and Observations $\ldots \ldots \ldots \ldots \ldots \ldots \ldots \ldots \ldots \ldots \ldots \ldots$

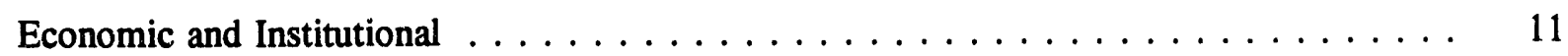

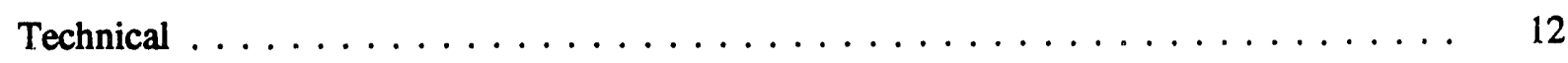

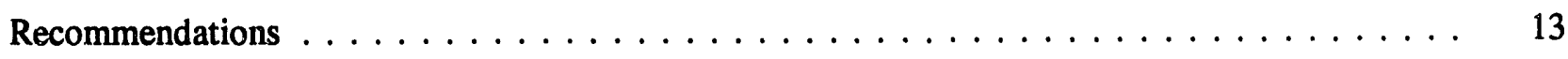

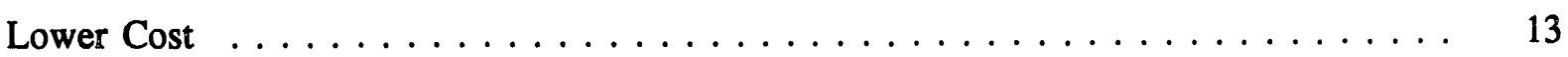

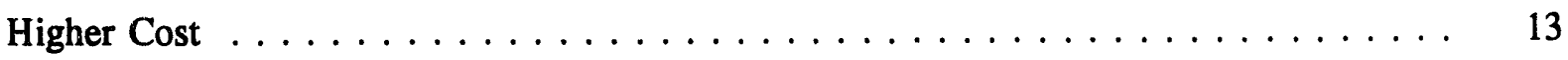

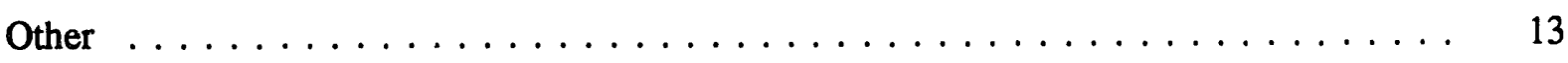




\section{Introduction}

In late 1990 staff from the U.S. Department of Energy's (DOE) Office of Technical and Financial Assistance identified the Polish-American Children's Hospital (Hospital) as a potential site for application of DOE expertise to reduce the Hospital's energy requirements. Visits to the hospital in the fall and winter of 1991-92 provided initial scoping of the energy related activities that would be supported by DOE. In addition to reducing energy requirements, the Hospital staff expressed a need for assistance in the areas of power quality and medical waste incineration. Subsequently, a power quality study supported by the Electric Power and Research Institute has been initiated and medical waste incineration will be provided by a Polish organization.

The resulting scope of work for this effort is to survey the Hospital's thermal energy supply and demand systems to identify no-cost and low-cost measures that will reduce the Hospital's energy requirements. Applicable measures would then be demonstrated in the Hospital through a partnership with U.S. and Polish organizations and a sister hospital in the United States.

A team of researchers from the Pacific Northwest Laboratory and RDA Engineering, Inc., visited the Hospital in March and October 1992, to gather additional information on the Hospital's thermal energy systems in order to focus a detailed assessment on priority areas. This report provides a description of the Hospital facility and energy systems, priority areas identified by the Hospital staff, and the U.S. team's recommendations for focusing the subsequent actions. 


\section{Facility Description}

This section of the report provides a description of the Hospital facility and its energy supply and demand systems. Following the overview sections, subsections provide additional notes and information on major working areas of the facility, such as the boilers, the hot water distribution system, heat exchanger nodes and building systems.

\section{Facility Overview}

The Polish-American Children's Hospital has been operating at its current complex in Krakow for 28 years. The Hospital provides outpatient care and a total of about 600 beds in a building complex composed of four major sections as shown in Figure 1. The first section, completed in 1964, is primarily a 4-story structure that provides pediatrics care and has 330 beds. The second section, completed in 1974, is 3 stories and provides laboratory space. The third section, completed in 1987, is the rehabilitation center which has 240 beds. A fourth section, scheduled for completion during late 1992 or early 1993, will provide ambulatory care and will have 45 beds. This fourth section will increase the Hospital's heated space from about $100,000 \mathrm{~m}^{2}$ to a total of $350,000 \mathrm{~m}^{2}$. There are also 20 beds in the intensive care unit (ICU) and 14 beds in ICU recovery.
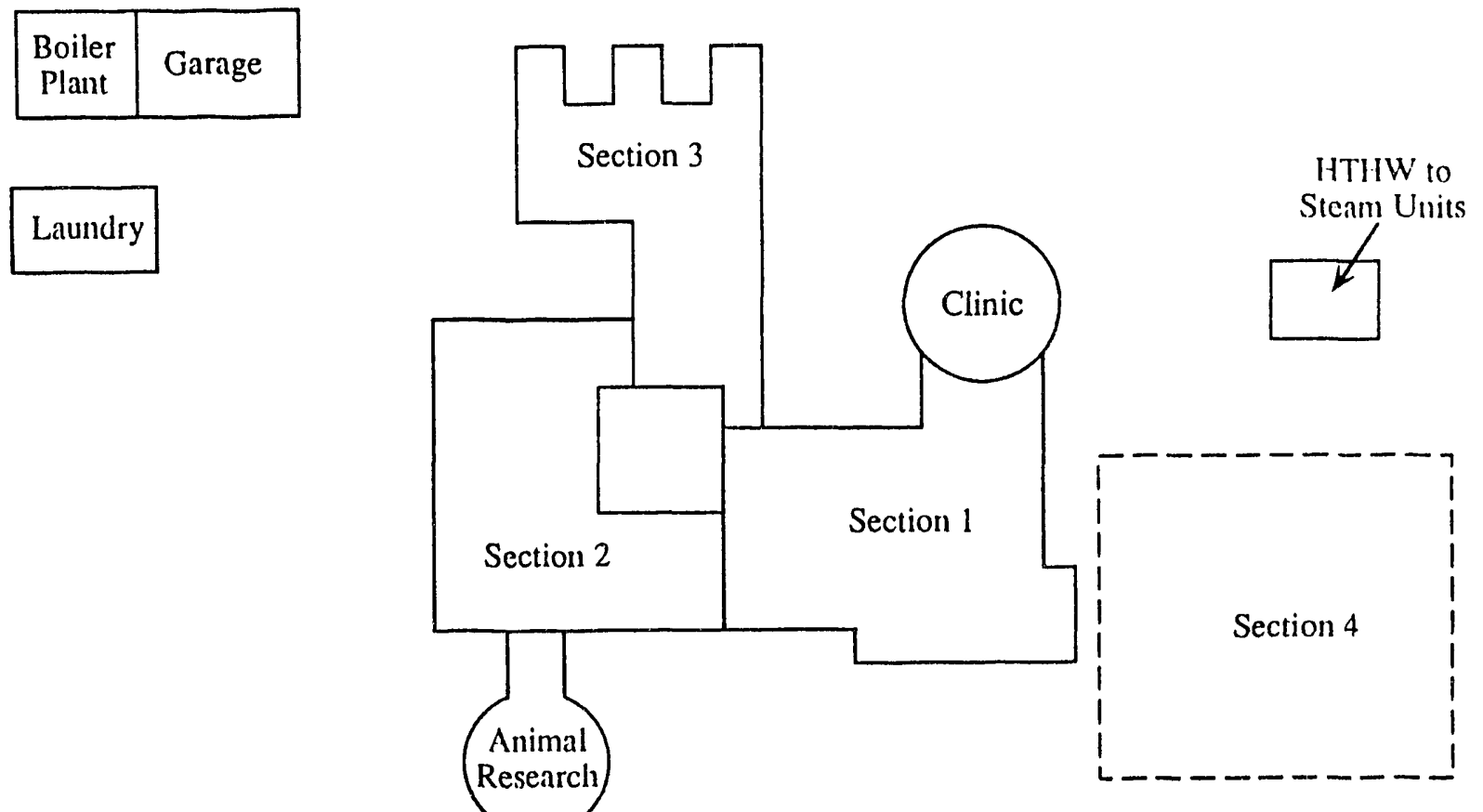

Figure 1. Schematic of Main Hospital Complex 
Other buildings in the complex served by the coal-fired boiler plant include a nurse's dormitory (about 200 nurses), three student dormitory buildings for medical academy students, a cafeteria for these dormitories, and a large geriatrics center. A pharmaceutical center and cafeteria are under construction and scheduled for completion in late 1992 or early 1993. The Hospital is responsible for maintaining the heating and hot water systems for the nurses dormitory; geriatrics center staff have responsibility for maintaining their systems. The Nicolas Copernicus Academy of Medicine in Krakow is responsible for the student dormitories and cafeteria. Thermal energy is provided to a heat exchanger station at these buildings; in-building maintenance is provided by Academy staff.

There apparently is a long-term plan for relocation of the Medical Academy from downtown Krakow to the Hospital campus near the student dormitories and pharmaceutical center. Because of the current economic problems, there is no construction or relocation schedule.

Total hospital staff is about 1500 for about 600 beds which is high by Polish standards. The 2.5:1 staff to patient ratio compares to a reported typical Polish hospital ratio of 2:1 and U.S. hospital ratio of 5:1. The high staffing is required to operate the research facility and extensive newborn care.

\section{Thermal System Overview}

Space heat and steam generation is provided primarily by a coal-fired power plant, referred to as Biezanow, located about $3 \mathrm{~km}$ from the hospital complex (see Figure 2). This plant consists of two field-erected water tube hot water generators rated at 5 to 6 gigacalories (boilers number 1 and 2) and one field-erected water tube hot water generator rated at 6 to 7 gigacalories (boiler number 3). Boilers number 1 and 2 have chain grate stokers and boiler number 3, which was recently rebuilt, has a spreader stoker. A staff of 20 operates this heating plant 24 hours a day.

The high-temperature hot water (HTHW) distribution line from the power plant to the hospital complex provides $175^{\circ} \mathrm{C}$ hot water at 14 atm of pressure. Construction of a new 300 -mm diameter distribution line was started 6 years ago and completed in February 1992. The new distribution line was installed in parallel with the original $200-\mathrm{mm}$ diameter line, allowing for phased construction so the old line could be used as a backup. The old line was poorly insulated, badly corroded (experiencing approximately 10 major leaks per year), and undersized for the current heating load. The original $100,000 \mathrm{~m}^{3}$ hospital will have expanded to $350,000 \mathrm{~m}^{3}$ with the addition of the fourth section. The new line is cross-connected with the old line at several points between the plant and the hospital. Leaking valves between these lines continue to be a problem.

Each building's local space heating distribution system pressure and temperature are maintained independently via heat exchangers connected to the HTHW distribution system. Steam generated from the HTHW system at 4 atm is used for three sterilizers, a laundry, and kitchens at the hospital and dormitories. Steam is generated on the main campus at a steam plant using HTHW and provided via steam heat exchangers to each student dormitory and cafeteria. Minimal backup hot water is provided by electric water heaters. The laundry boiler plant produces steam at 6 atm for process uses, primarily irons and presses. Hot water is supplied to one backup sterilizer by the laundry's boilers. 
Biezanów

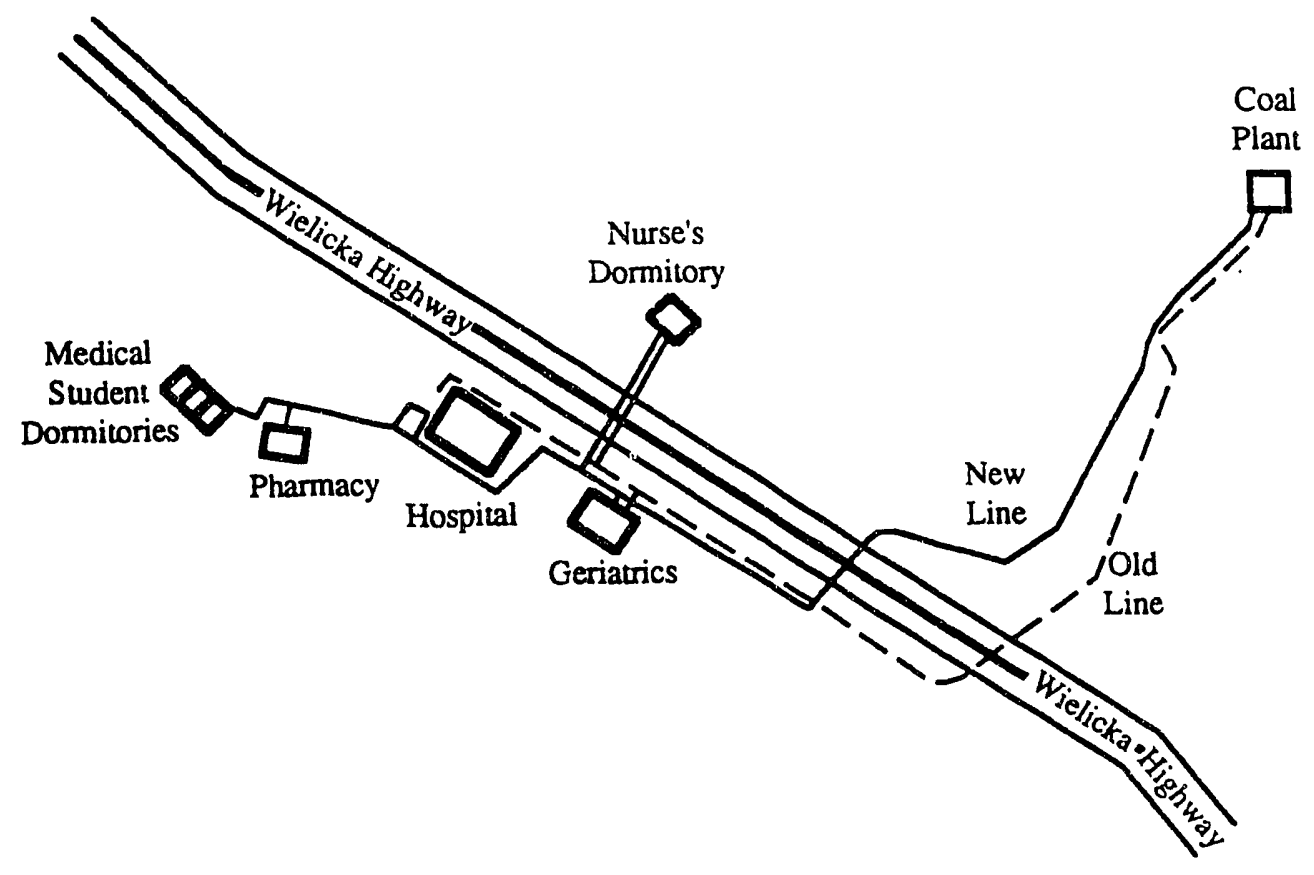

Figure 2. Schemetic of Thermal Distribution System

Supplemental or emergency space heat can be provided in hospital buildings via heat exchangers connected to the municipal district heating system (MPEC). But, because MPEC's heating system lines are very long (the hospital is at the end of the current distribution system), the water temperature is sometimes low. The MPEC system operates only during the heating season. Since the hospital requires heat year round for domestic hot water and steam, the MPEC system is used for space heating only. The MPEC system is not designed to provide emergency domestic hot water and is not hot enough to generate steam for the sterilizers. There are a few emergency electric hot water heaters scattered throughout the hospital.

Steam at 6 to 7 atm for the hospital laundry and one backup sterilizer is provided by three $150 \mathrm{psi}, 50$-BH Cleaver-Brooks fire tube steam boilers at a power plant located at the main hospital complex. These boilers are natural-gas-fired and use nuniber 2 fuel oil backup. However, space heat and hot water for the laundry are supplied by the coal-fired power plant's HTHW system.

Air conditioning (cooling) is considered necessary only 2 to 3 weeks per year. If air conditioning were available, it may be considered necessary for a longer period. A Carrier absorption chiller provided air conditioning for the surgery rooms from 1967 to 1987 . This unit was deactivated due to the high maintenance cost. Two Trane package air cooled chillers will be installed at the HTHW steam generation plant as part of the fourth section building construction. Air conditioning is currently provided to select laboratories, offices, etc., by approximately 50 to 60 window units. 
There is a central control room and monitoring system (circa 1965-67) that has very limited capability for monitoring operations and maintaining temperature set points and cycling equipment operation within the hospital building. Section three (the rehabilitation center) has Polish and East German controls. The remainder of the control systems were from Honeywell and are 25 years old. All the control systems are pneumatic. The problems with the Honeywell control systems are due to age, parts availability, technical support availability, and operator training. There is some overheating in the building. There is very little in-line temperature and pressure monitoring equipment, and no thermal energy meters, within the complex.

There are persistent problems with fouling, corrosion, and leakage in all hot water systems. Many of the original steel heat exchanger tube bundles have been replaced with copper tube bundles by the hospital staff. Most heat exchanger tubes require yearly cleaning because of fouling. Many of the heat exchangers, hot water tanks, and much of the hot piping are not insulated because of lack of funds.

Following are specific heating equipment status notes for each hospital section, other distribution system buildings, and HTHW generators and the distribution system.

\section{First Hospital Section}

Space heat, humidification, and domestic hot water (DHW) are provided to the first hospital section by the main HTHW plant through heat exchangers. Hot water is provided at $60^{\circ} \mathrm{C}$ for the first and second sections.

\section{Second Hospital Section}

Space heat, humidification, and DHW are provided to the second hospital section by the main HTHW plant through heat exchangers. The hospital does not heat domestic hot water using the MPEC system because it does not have a permit to do so.

\section{Third Hospital Section}

Space heat is provided to the third hospital section by MPEC through heat exchangers. Space heating service from MPEC cost about $\$ 100,000$ during the last heating season. Humidification and DHW are provided by the main HTHW plant through heat exchangers. The hospital HTHW distribution system did not have adequate capacity to heat this section until installation of the new $300-\mathrm{mm}$ diameter line.

The staff working in this section have complained about how cold the building is during the winter. This is due in part to the original curtain wall construction, which is composed of $20-\mathrm{cm}$ thick brick and a 10-cm air space, and in part to the low temperature of the MPEC system water because the hospital is at the end of the MPEC distribution system. There may also be control and fouling problems in this section's low temperature hot water system. About 1 year ago, exterior walls for the offices (not in hallways) in the third section were retrofitted with mineral wool insulation in the $10-\mathrm{cm}$ air space. Even with the added insulation many offices still use portable electric heaters 
to supplement the radiators. This problem may be solved when this building section is heated by the higher temperature hospital HTHW system, which should begin during the 1992-93 heating season.

\section{Fourth Hospital Section}

Space heat will be provided to the fourth hospital section by MPEC through heat exchangers. Humidification and DHW will be provided by the main HTHW plant through heat exchangers. The hospital HTHW distribution line did not have adequate capacity to heat this section until installation of the new $300-\mathrm{mm}$ diameter line. There are concerns that the distribution system pumps are undersized (they were not replaced) for this new load. It is estimated that boiler plant output may be increased by 15 to $20 \%$ by properly sizing the pumps and piping at the main boiler plant.

\section{Medical Academy Campus}

The three medical academy dormitories were built approximately 10 to 15 years ago. This complex is managed by the medical academy, not the hospital. All space heat is provided by MPEC system water directly--there is no hydro-elevator or heat exchanger. There is a flow limiter which is changed by MPEC two to three times a year. The main power plant HTHW system provides DHW and steam for the cafeteria via heat exchangers. The DHW makeup water system contains a magnetic water softener.

The pharmaceutical dormitories and cafeteria are designed to operate as described above. There are plans to move the medical university and other medical facilities to this complex.

\section{Main HTHW Power Plant}

The three coal-fired hot water generators are about 30 years old. If they operated properly, they could meet all the hospital complex's thermal energy requirements (except the laundry's steam requirements). This plant consists of two field-erected water tube hot water generators rated at 5 to 6 gigacalories (boiler numbers 1 and 2) and one field-erected water tube hot water generator rated at 6 to 7 gigacalories (boiler number 3). Boiler number 3 was originally configured like boilers 1 and 2 with chain grate stokers but was recently rebuilt and converted to a spreader stoker. In the summer, only one boiler is used and in the winter either the 6 to 7 gigacalories or the two 5 to 6 gigacalories boilers are operated, indicating that the current load on this power plant is approximately 7 gigacalories.

New pipes in the 6 to 7 gigacalories boiler should increase its capacity to 8 gigacalories. With the fourth building section coming on line, the load should increase to about 8 gigacalories.

The water temperature leaving the power plant is about $175^{\circ} \mathrm{C}$. Line loss results in a supply for the hospital of about $165^{\circ} \mathrm{C}$, and a supply for the medical academy dormitories of about $155^{\circ} \mathrm{C}$.

Recent improvements are the retrofit of boiler number 3 from a chain grate to spreader stoker feed (1989), a new thermal distribution line (1992), and ongoing installation of new 45-m high stacks (1992). Additional improvements needed include particulate control and desulphurization (estimated cost is about $\$ 600 \mathrm{~K}$ ), retrofit of the other two boilers from chain grate to spreader stoker, increased 
pumping capacity to fully utilize the increased distribution line size, and replacement or repair of piping within the plant. It is estimated that the boiler plant output may be increased by 15 to $20 \%$ with new pumps and piping at the plant; these improvements are currently undergoing design. Permit applications have been made to install particulate and desulphurization equipment and contract negotiations are in process for financing and purchasing the equipment.

Coal consumption has been relatively constant at about 10,000 metric tons per year. The coal used is cheap and appears to be of low quality with significant fines.

The low temperature design point of the plant is -20 to $-25^{\circ} \mathrm{C}$. The typical low winter temperatures experienced are in the $-10^{\circ} \mathrm{C}$ range.

Operation and maintenance of this coal-fired power plant requires a staff of 20 employees. There is an apparent lack of regular maintenance--the plant is very dirty, many pumps and associated equipment are torn down and in disrepair, and insulation is deteriorated. This is due to the lack of staff and funding resources to schedule and perform routine maintenance. The boiler plant staff are reportedly able to take the system down for maintenance only about 6 days per year which is not adequate.

The leaks experienced in the original HTHW transmission line were typically located at the weld joints near expansion loops. This indicates corrosion and/or poor welds, with leakage occurring first near stressed joints. The new HTHW pipe appears to be seamless, but there was no indication of field weld quality.

\section{Hospital Laundry Steam Power Plant}

Steam at 6 to $7 \mathrm{~atm}$ for the hospital laundry and one backup sterilizer is provided by three U.S.made gas-fired Cleaver-Brooks steam boilers. All three of the boilers were supplied by Project Hope but without any operations documentation, and attempts to obtain documentation were unsuccessful.

The original main power plant HTHW to laundry hot water heat exchangers were installed in 1983, and had to be replaced by 1991 because of fouling and corrosion leakage. A shell and tube heat exchanger designed to use the warm water from the laundry's washing machines to pre-heat fresh water is not operating because of continued fouling.

One emergency steam sterilizer is supplied by the laundry steam plant.

\section{HTHW and Heating Water Quality}

Both the main and laundry power plant designs provide for boiler makeup water which is softened and deaerated (oxygen and carbon dioxide). Sodium softening is used to replace calcium and magnesium. Phosphate could be added but residual hardness is very low- -0.02 to $0.04 \mathrm{ml}$ per liter. Calcium content is 1 to $2 \mathrm{ppm}$. Given these low levels, it is not necessary to add phosphate. (Based on information from the Hospital's water quality manager.) No other water treatment chemicals are used. 
Unfortunately, the deareator at the coal-fired power plant has been inoperative for at least 6 months and operated intermittently before because of control problems. Not surprisingly, rust was observed to be the main component of fouling, although the staff indicated that calcium buildup is also a problem. Sometimes the water treatment station cannot keep the water sufficiently softened because of high water makeup rates of up to $20 \mathrm{~m}^{3} /$ day. Fifty-kilogram bags of salt used in the water softener must be manually carried up two stories of stairs, which may bear upon the ability and/or incentive for adequate water treatment.

Cost is the main reason for not using corrosion inhibitor chemicals. The local facilities maintenance staff is aware of the tremendous staff resources that could be re-directed from corrosionrelated leak repair and fouling cleanup if a thorough water quality program were started. The staff is worried that if pipes were chemically cleaned now, there could be a massive short-term leakage problem. It needs to be pointed out that water treatment will have a long-term payoff and increased energy efficiency. Information was provided on chemical cleaning technology and various types of coal boilers.

The original hot water system designs had no basic sand or particulate filtration. Now, whenever there is any system maintenance, there is a release of rust/calcium/sand matter that floats throughout the system until it plugs a control valve. Some basic filtration is needed. 


\section{Comments, Issues, and Observations}

ithis section provides additional information and summarizes main points from the text of the report that relate to the recommendations provided in the last section.

\section{Economic and Institutional}

The curren'. price of natural gas is about $1840 \mathrm{Z} / \mathrm{m}^{3}(\sim \$ 0.13)$ versus $1570 \mathrm{Z} / \mathrm{m}^{3}(\sim \$ 0.11)$ for industrial customers and is projected to increase b: $5 \%$ quarterly. In January, the hospital paid about $300 \mathrm{~K} \mathrm{Z} /$ metric ton $(\sim 21)$ for $12,000 \mathrm{Btu} / \mathrm{lb}$ coal-this compares to about $400 \mathrm{~K} \mathrm{Z} /$ metric ton $(\sim 30)$ for residential consumers. The price of coal is projected to increase by $5 \%$ per month. The relative cost of gas versus coal appears similar to that in the U.S.

The Hospital Director of Engineering has responsibility for about 117 staff. Turnover is high due to the low salary structure (about $1.5 \mathrm{M}$ Zloty/month or $\$ 110$ plus $47 \%$ employer paid taxes and uniforms), which is set by the government. The director has more staff than a normal hospital because of the coal-fired power plant and the research nature of the hospital. The director does not have any incentive to control cost because he does not manage his own budget.

Total hospital staff is about 1500 for about 600 beds which is high by Polish standards. This high ratio is due to the presence of the research facility and newborn care. Typical Polish staff to patient ra $a^{\wedge}$ io is about 2:1, Children's Hospital is 2.5:1, and U.S. hospitals are about 5:1.

The contracts with MPEC for space heating require a 1-year prior notice to terminate. A termination notice has not been given for the contract for section three (although the hospital's H'THW system should now have adequate capacity). Section four will operate using MPEC space heating indefinitely.

Public pressure exists to reduce emissions from the main plant and the medical waste incinerator.

It is estimated that the Hospital can generate heat at about half the cost of heat purchased from MPEC, so purchased heat is minimized. It is not clear how the Hospital's energy costs are calculated-including coal, labor, equipment operations and maintenance, and depreciation. The estimated cost savings may well be based only upon the coal cost of about $\$ 0.90 / \mathrm{MBtu}$ versus $\$ 2.00 / \mathrm{MBtu}$ for heat purchased from MPEC.

As in most hospitals, the medical facilities and equipment receive priority over facility planning and maintenance. 


\section{Technical}

A second-stage particulate removal system may be sufficient to reduce emissions to acceptable levels. There does not appear to be a master plan in place for the hospital facility, much less for planning thermal system improvements and maintenance.

The city design office is preparing a new design of the existing deaerator for water treatment. The focus is deaeration (oxygen and carbon dioxide); chemical treatment for oxygen scavenging or corrosion inhibitors is not being considered.

The third section of the building has been uncomfortably cold in the winter in past years because the temperature of MPEC-delivered energy is reportedly too low.

Plant efficiency could be improved by upgrading the coal feeds on boilers 1 and 2, installing combustion controls, installing new pumps and piping, and installing automatic controls.

There is uncertainty about the adequacy of the level of insulation on the HTHW distribution line from the main plant to the Hospital complex.

Very limited electrical backup exists for sterilization and hot water.

If the old heaing plant is kept, the Director of Engineering's priorities are

- New pumps and pipes in the power plant to fully utilize the new $300-\mathrm{mm}$ distribution lines.

- Renovate boiler number 1 with new coal feed and boiler tubes.

- Install particulate control and desulphurization equipment.

A demand side priority would be to improve controls.

Heavily fouled (mostly rust) and therefore energy inefficient heat exchangers should be replaced. 


\section{Recommendations}

Prior to proceeding with any improvements to the physical systems, we feel it is essential to characterize the thermal system serving the Hospital to document the supply, distribution, and use of thermal energy in the Hospital. This characterization is needed to proceed with any of the actions listed below and to more effectively meet the thermal energy requirements of the facility additions under way as well as planned.

\section{Lower Cost}

- Initiate complete water treatment program (chemical and mechanical cleaning, correct water softener and deaerator problems, and install continuous chemical treatment for oxygen scavenging and corrosion inhibitors), install double-wall heat exchangers for all DHW, and provide maintenance and operator training.

- Upgrade existing pneumatic controls and provide operator training.

- Reduce HTHW supply temperature from main power plant by installing small gas-fired steam generators on-site where required (sterilization and kitchens). Use on-site gas generation for hot water in the summer. Reschedule sterilization and laundry operation hours.

- Outline problem areas and opportunities for more efficient operation and maintenance of the facility and develop and implement a commensurate scheduling and training program.

\section{High Cost}

- Upgrade the existing coal plant with improved coal feeds; combustion controls; particulate control equipment; and new piping, pumps, and controls.

\section{Other}

- Explore MPEC operation or purchase of the existing or new power plant and with a guarantee of service. The Hospital could use the proceeds to build steam capacity for sterilization and kitchen uses. 

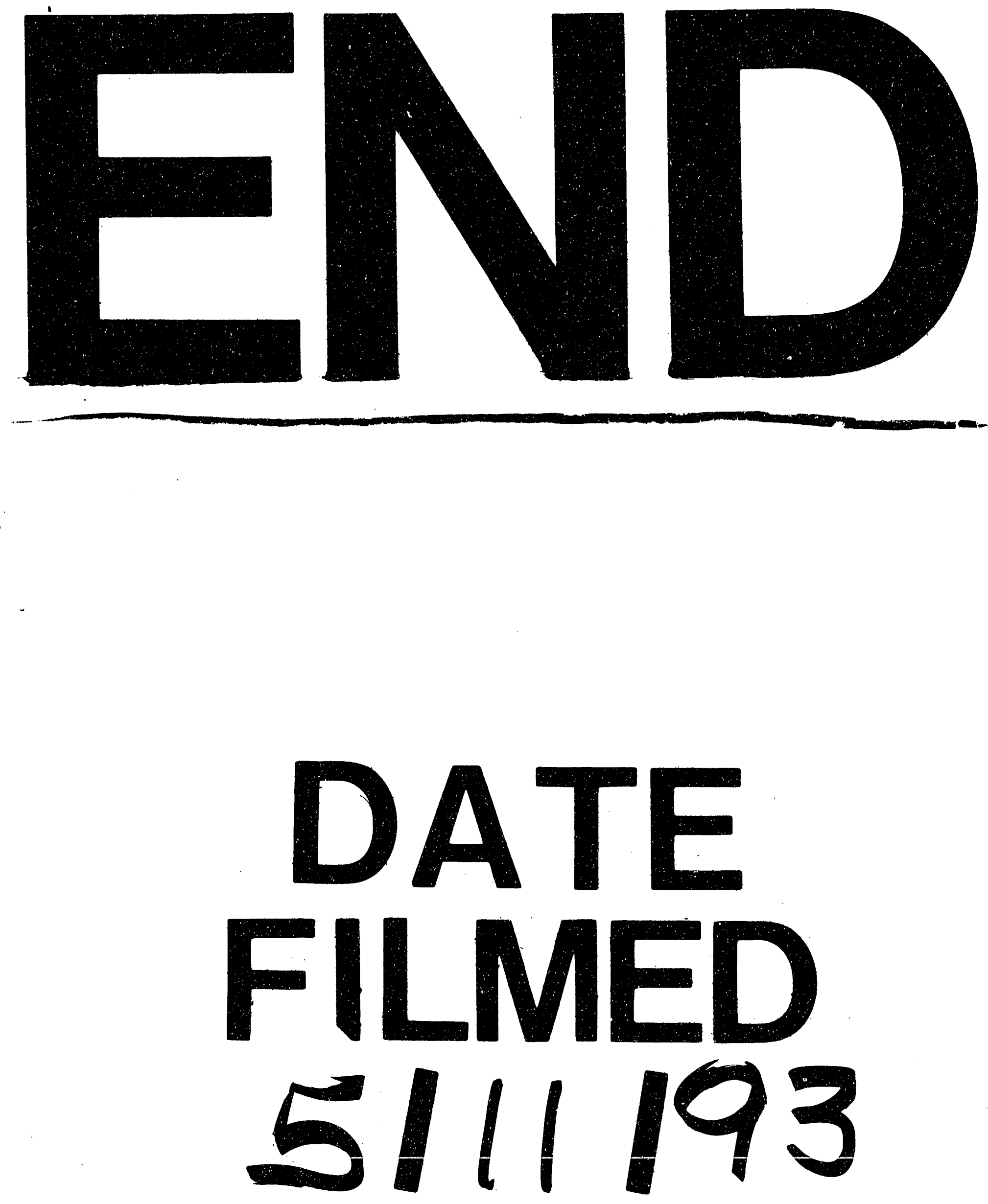
